\title{
Biosensor Implementation in Haemodialysis Monitors to Improve Treatment Quality
}

Gianmario Bosticardo ${ }^{1 *}$, Susy Doratiotto ${ }^{1}$, Cristina Bonfatti ${ }^{1}$, Miriam Borin ${ }^{1}$, Paolo Detoma², Emanuela Lanza ${ }^{2}$, Enrico Schillaci ${ }^{1}$ and Roberto Bergia1 ${ }^{1}$ Nephrology and Dialysis Unit, Hospital-Territory Department, ASLBI, Biella, Italy ${ }^{2}$ Laboratory Unit, Services Department, ASLBI, Biella, Italy

\section{Editorial}

Since haemodialysis therapy has been started, a progressive technological improvement has been made. The first human dialysis were simply performed with a blood pump and an air bubble trap [1]; later pressure transducers in the extracorporeal circuit were provided, whereas dialysis fluid was prepared by direct mixing of water and electrolytes. A second generation of haemodialysis monitors was characterized by automated preparation of dialysis fluid, through proportioning devices regulated by adjustment of conductivity and ultra filtration control. Since these machines have been progressively ameliorated by employing microprocessor and computer technology and by implementing various modules such as blood volume monitor, blood temperature and recirculation test, ionic dialysance or UV absorbance with the aim of surveying dialysis efficiency. In the past years a urea monitor (Baxter Renal Division, Deerfield) was employed to directly quantify dialysis adequacy at bed-side, showing a good reliability [2]: nevertheless, this system was abandoned due to its excessive cost.

The adoption of biosensors and biotechnology on board of haemodialysis machines is still to be considered very poor and has to be extended further in future years.

\section{Next-generation haemodialysis monitors}

Although an impressive technological improvement of haemodialysis machines has been realized, until now the electrolyte concentration is not directly measured in the dialysis fluids. Recently, we have performed studies regarding calcium mass-balances in haemodialysis, calculated by measuring ionized calcium in the dialysate and blood at the start and end of each run, using a kinetic formula to define the mean concentrations in the blood and dialysate and then estimating CMBs over the entire treatments $[3,4]$ : through the implementation of ionized calcium micro-flow electrodes, which are actually commercially available, the calcium mass-balance could be directly measured without the need of sampling and laboratory determinations, thus improving the adequacy of dialysis.

The same principle could be applied to other electrolytes and uraemic substances, as micro flow electrodes have been realized over 25 different species including $\mathrm{pH}, \mathrm{pO}_{2}, \mathrm{pCO}_{2}, \mathrm{Na}, \mathrm{Cl}, \mathrm{K}$ and redox potential.

In Table 1 is a summary of a single case study in which electrolyte and uraemic markers mass balances have been studied in detail, by sampling blood and ultra filtrate at the start and at the end of dialysis, and by continuous spilling of a dialysate sample: these results too are interesting and may be usefully employed to optimize the dialysis adequacy. The implementation of biosensors on board of haemodialysis monitors might therefore be useful to automatically survey the solute mass transfer across the dialysis membrane. The haemodialysis monitors should also be provided by automated sampling devices of fresh and spent dialysate, to allow for the laboratory measurement of the substances not yet detectable by on-line biosensors.

\begin{tabular}{|l|l|l|}
\hline & OUT $\mathrm{mg}$ & SRI dimensionless \\
\hline urea & 8026.2 & 1.59 \\
\hline creatinine & 674.2 & 1.36 \\
\hline phosphate & 361.2 & 1.21 \\
\hline$\beta 2 \mu \mathrm{g}$ & 3.2 & 0.02 \\
\hline
\end{tabular}

Table 1: Example regarding an 87 years-old female showing inadequate depuration. Direct measurement of uremic solutes removal by spent dialysate partial collection, with their relative Solute Removal Index [5].

\begin{tabular}{|l|l|l|l|}
\hline & IN mmol & OUT mmol & MB mmol \\
\hline $\mathrm{Na}$ & 11296.8 & 11316.9 & -20.1 \\
\hline $\mathrm{K}$ & 235.3 & 272.1 & -36.7 \\
\hline $\mathrm{Ca}$ & 235.3 & 224.7 & +10.6 \\
\hline
\end{tabular}

Table 2: Same case of Table 1: example of direct measurement of electrolytes mass-balance obtained by spent dialysate partial collection. While sodium and potassium mass-balances may be considered adequate, calcium positive balance (corresponding to $+424.7 \mathrm{mg}$ ) may be considered excessive.

\section{Future-generation haemodialysis monitors}

As well as the on-line measurement of dialysis solute mass-balance, the implementation on board of haemodialysis monitors of on-line biosensors could possibly be useful to individualize any single treatment needed to the patient. In future dialysis machines the preparation of dialysis fluid for example could be obtained by the separate mixing of the native salts as sodium, potassium, calcium and magnesium chloride, and sodium bicarbonate (instead of simply proportioning pre-mixed concentrate solutions with fixed electrolyte concentrations, as in dialysis monitors presently employed). By employing computerized technology combined by biosensors the solute profile during the treatment could be optimized, thus improving the safety and adequacy of dialysis.

\section{References}

1. Haas G (1923) Dialysieren des strömenden Blutes am lebenden. Klin Wochenschr 2: 1888.

2. Bosticardo GM, Avalle U, Giacchino F, Molino A, Alloatti S (1994) Accuracy of an on-line urea monitor compared with urea kinetic model and direct dialysis quantification. ASAIO J 40: M426-430

3. Bosticardo GM (2010) The diffusion gradient between ionized calcium in dialysate and plasma water-corrected for Gibbs-Donnan factor-is the main driving force of net calcium balance during haemodialysis. Nephrol Dial Transplant 25: 3458-3459.

*Corresponding author: Gianmario Bosticardo, Nephrology and Dialysis unit, University of Turin, Italy, Tel: +39-0125727311; E-mail: gmbostic@alice.it

Received March 22, 2012; Accepted March 23, 2012; Published March 25, 2012

Citation: Bosticardo G, Doratiotto S, Bonfatti C, Borin M, Detoma P, et al. (2012) Biosensor Implementation in Haemodialysis Monitors to Improve Treatment Quality. J Biosens Bioelectron 3:e108. doi:10.4172/2155-6210.1000e108

Copyright: (c) 2012 Bosticardo G, et al. This is an open-access article distributed under the terms of the Creative Commons Attribution License, which permits unrestricted use, distribution, and reproduction in any medium, provided the original author and source are credited. 
Citation: Bosticardo G, Doratiotto S, Bonfatti C, Borin M, Detoma P, et al. (2012) Biosensor Implementation in Haemodialysis Monitors to Improve Treatment Quality. J Biosens Bioelectron 3:e108. doi:10.4172/2155-6210.1000e108

Page 2 of 2

4. Bosticardo G, Malberti F, Basile C, Leardini L, Libutti P, et al. (2012) Optimizing the dialysate calcium concentration in bicarbonate haemodialysis. Nephrol Dia Transplant.
5. Keshaviah $P$ (1995) The solute removal index--a unified basis for comparing disparate therapies. Perit Dial Int 15: 101-104. 